\title{
Effective Technological Schemes for the Cultivation of Industrial Open-Earth Vineyards in the Don Area
}

\section{Huseynov Shamil ${ }^{1}$ and Mayborodin Sergey ${ }^{2}$}

${ }^{1}$ All-Russian research Institute of wine and viticulture named after Ya. I. Potapenko-branch of the
Federal state scientific institution "Federal scientific agrarian center", Novocherkassk, Russian
Federation
${ }^{2}$ Federal State Budgetary Educational Institution of Higher Education "Don State Agrarian
University", Persianovski, Russian Federation ORCID:

Huseynov Shamil: http://orcid.org/0000-0003-3654-0132

\section{Abstract}

Over the long years of the development of agro-technological approaches to the methods of grape growing, researchers paid special attention to the issues of pruning grape bushes, the methods of their formation and maintenance and planting plans. In the environmental conditions of the Lower Don of the Russian Federation, many years of research were conducted in order to establish the optimal parameters of various agro-technological methods used in the vineyard (the methods of maintaining, forming, pruning and the rates of bush loading) through the example of a promising variety of Crystal grapes of interspecific origin. At the same time, a prerequisite for this research was the link with the scheme of planting vines and its effect on the productivity of uncultivated vineyards, as well as the quality of the crop. In this study, we proposed the technological and economic advantages of industrial and intensive methods of maintaining and forming vineyards on an industrial basis. These methods were new for the Don conditions. We conducted research and studied various ways of maintaining, forming, pruning and loading grape bushes in the Rostov Region, in the conditions of the experimental field, which increased the use of photosynthetic active radiation (PAR) in the production process on standard open-earth vineyards of industrial and intensive type, when cultivating Crystal grape varieties of interspecific origin. Processing and analysis of the results of the application of various agricultural methods in the experimental areas will reveal the most optimal ones from an economic point of view.

Keywords: grapes, architectonics, management method, productivity, biomass

\section{Introduction}

First of all, in order to obtain the maximum effect during the cultivation of a vineyard, it is necessary to establish the sizes of plants, which are determined by the accepted 
methods of maintaining, forming and pruning grape bushes. It is equally important to form the architectonics and architecture of the vineyard (appearance), which allows creating conditions for an optimal nutrition regime of plants and providing them with the necessary conditions for growth and fruiting. They allow more full realization of the potential of grape bushes in the specific conditions of plant growth. Therefore, the study of the reaction of a vine plant in the manifestation of the main agrobiological signs, using various agro-technical methods, is of great scientific and practical interest.

\section{Methods and Equipment}

The grafted vineyards (Kober 5BB rootstock) of Crystal varieties were located in the area of Novocherkassk, Rostov Region. The vineyards were formed in the spring of 2006 according to the scheme $3.0 \times 0.5-0.7-1.5 \mathrm{~m}$.

The field experiment was set up in 2011, and the statistical analysis of the experimental data was carried out in accordance with the methodology of the field experiment according to B.A. Dospekhov. Agrobiological surveys and observations were performed according to the generally accepted methodology of agrotechnical research $[3,4]$.

The experimental vineyards allowed various methods of plant management. In addition, they included planting schemes, methods of forming and pruning bushes.

During many years of the experiment, we studied the following: a small cupped formation, single and doubled Guillot, zigzag cordon, 2-sleeved high-punched, Y-type, heart-shaped umbrella (the first five of which are protected by patents for inventions) and such methods of performance as simplified single tier trellis (100 cm high) and standard 2- and 3-tier vertical trellis.

\section{Results}

As a result of numerous studies carried out both in our country and abroad it was found that among the variety of agro-technical techniques used in the vineyard, the most powerful impact on the vitality of a grape plant is exerted by the methods of maintaining, forming and pruning bushes. These agricultural methods allow giving the plants a specific configuration that is most effective for the assimilation of photosynthetic active radiation (PAR) falling on the plants and contribute to the broad mechanization of the processing of vineyards. The optimization of the above parameters of agricultural methods contributes to the creation of conditions for the development and rational placement in the plane of the trellis of leaf-stemming apparatus $[5,6]$. 
In specific environmental conditions the parameters of a grape bush in a vineyard are interrelated both by the biological characteristics of cultivated varieties and mainly by the rate of bushes loading. The nature of the placement of the leaf apparatus in relation to the PAR falling on the plants, are interrelated with methods of maintenance, which in turn determine the structure of the bushes, i.e. their architectonics and the volume of the crown space where the leaf-stemming apparatus is located.

Otherwise things being equal the productivity of PAR depends on the density of leaves in a unit of crown space. Therefore, during the creation of highly productive plantations, it is necessary to create conditions for the increase of crown space of bushes, which can increase the plants loading with a leaf-stem apparatus without loss of radiation and temperature conditions. They help to increase the productivity and economic efficiency of grapes. In this case, it is necessary to take into account not only the biological characteristics of the varieties, the climatic conditions of the regions, but also the methods of cultivation, as well as the direction in the use of the crop $[4,7]$.

In the course of the studies we noted that the Crystal grape variety is very sensitive to the applied agricultural practices, first of all to the scheme of planting bushes, formation and the method of maintaining and pruning.

This effect was reflected in the size of plants, and, consequently, in the formation capacity in relation to bushes loading. Thus, the transition to high-standard vineyard management systems with free development of the leaf-stemming apparatus allowed increasing the rate of plant loading by $15-20 \%$, compared to medium-stem formations with vertical growth on the trellis. A similar trend was noted in medium-standard stands with the use of compact planting of bushes with small cupped and other bushes. The data are given in table 1.

The objective biological indicator by which it is possible to assess the reaction of a variety to the conditions of the growing environment are the indicators of the fruitfulness of shoots, which are closely related to the growth energy of the shoots. As a rule, the plants that are characterized by increased values of these indicators are more productive.

The maximum economic effect from the cultivation of a particular grape variety under certain environmental conditions can be achieved only by the creation of favorable conditions in the vineyard for the growth and development of shoots that contribute to high initiation of generative organs in the buds of wintering eyes $[8,9]$.

We noted that Crystal variety, under the conditions of the experiment, was characterized by very high fruitfulness, and therefore did not significantly respond to the method of maintaining and forming, and even to loading standard of the bushes. The proportion 
of fruitful shoots in all variants of the experiment was high (from 89 to 99\%). The data is presented in Table 1.

At the same time, it is necessary to note the advantage of this indicator in the formation of a small cupped, where a short pruning of vines was used. Thus, the analysis of the data in Table 1 shows that in the plantations with relatively large bushes (zigzag cordon, 2-sleeved high-stemmed, Y-type), the proportion of fruiting shoots in the total structure of bush loading was in the range from 89 to $93 \%$, in plantations with a small cupped formation of 95 - 99\%.

TABLE 1: The fruitfulness and productivity of shoots of Crystal grape variety, with a different planting pattern and method of forming bushes in average for 2011 - 2019

\begin{tabular}{|c|c|c|c|c|c|c|c|}
\hline \multirow{2}{*}{$\begin{array}{l}\text { Bush } \\
\text { formation }\end{array}$} & \multirow{2}{*}{$\begin{array}{l}\text { Planting } \\
\text { pattern, } \\
\text { m x m }\end{array}$} & \multicolumn{2}{|c|}{ Loading standard, shoots } & \multirow{2}{*}{$\begin{array}{l}\text { Fruiting } \\
\text { shoots, \% }\end{array}$} & \multicolumn{2}{|c|}{ Coefficients } & \multirow{2}{*}{$\begin{array}{c}\text { Productivity } \\
\text { of shoots, } \\
\text { g/crop }\end{array}$} \\
\hline & & on a bush & th. ga & & $\mathrm{C}_{1}$ & $\mathrm{C}_{2}$ & \\
\hline \multirow[t]{2}{*}{ Zigzag cordon } & $3 \times 1,5$ & 28 & 62 & 90 & 1,61 & 1,78 & 193 \\
\hline & $3 \times 0,7$ & 15 & 71 & 93 & 1,80 & 1,94 & 232 \\
\hline \multirow{2}{*}{$\begin{array}{l}\text { 2-sleeved } \\
\text { high-punched }\end{array}$} & $3 \times 1,5$ & 24 & 53 & 92 & 1,54 & 1,67 & 220 \\
\hline & $3 \times 0,7$ & 14 & 67 & 93 & 1,71 & 1,84 & 227 \\
\hline \multirow[t]{2}{*}{ Y-type } & $3 \times 1,5$ & 27 & 60 & 89 & 1,44 & 1,62 & 176 \\
\hline & $3 \times 0,7$ & 15 & 71 & 93 & 1,67 & 1,80 & 209 \\
\hline \multirow[t]{2}{*}{ Small cupped } & $3 \times 1,5$ & 29 & 64 & 95 & 1,85 & 1,95 & 204 \\
\hline & $3 \times 0,5$ & 13 & 87 & 99 & 2,03 & 2,06 & 231 \\
\hline \multirow[t]{2}{*}{ Umbrella } & $3 \times 1,5$ & 26 & 56 & 88 & 1,50 & 1,70 & 200 \\
\hline & $3 \times 0,5$ & 14 & 86 & 93 & 1,50 & 1,76 & 177 \\
\hline \multirow[t]{2}{*}{ Heart-shaped } & $3 \times 1,5$ & 26 & 58 & 92 & 1,62 & 1,76 & 217 \\
\hline & $3 \times 0,5$ & 14 & 93 & 93 & 1,57 & 1,69 & 170 \\
\hline \multirow{2}{*}{$\begin{array}{l}\text { Guillot without } \\
\text { spurs }\end{array}$} & $3 \times 1,5$ & 24 & 53 & 89 & 1,46 & 1,65 & 195 \\
\hline & $3 \times 0,7$ & 14 & 67 & 93 & 1,64 & 1,76 & 185 \\
\hline \multirow{2}{*}{$\begin{array}{l}\text { Average for all } \\
\text { options }\end{array}$} & $3 \times 1,5$ & 26 & 58 & 91 & 1,63 & 1,79 & 201 \\
\hline & $3 \times 0,5-0,7$ & 14 & 77 & 94 & 1,74 & 1,85 & 204 \\
\hline $\mathrm{HCP}_{05}$ & \multicolumn{6}{|c|}{4,3} & 10,2 \\
\hline
\end{tabular}

Therefore, the Crystal variety in plantation of this type fits into the technological schemes of the cultivation of high-stemmed industrial vineyards, with the widespread use of mechanization in most technological operations, including mechanized pruning of bushes, providing short (3-5 eyes) pruning of vines.

In mid-stemmed plantations with bushes: Umbrella, heart-shaped, Guillot, long pruning of vines (10-15 eyes) is the main component, thus short pruning of vines is not effective in this regard $[2,10]$. 
In addition to the fruitfulness of the shoots the equally important indicator in characterizing the reaction of the bush to the applied agricultural practices is the size of bunch. It has decisive role in the formation of indicators of shoot and bush productivity. It was noted that the size of the bunch had a scheme of planting bushes. Thus, in average for all experiment variants, larger clusters developed with rare planting of bushes (130 grams versus $120 \mathrm{~g}$ ). Although in general this did not affect the indicator - "shoot productivity", which is confirmed by the data in Tables 1-2.

As a result we see that all the agro-technical methods used in the vineyard had an impact on the yield and quality of the berries. It was found that the grape variety determines the direction of use of the crop in specific environmental conditions, and advanced agricultural practices determine its maximum possible value with the required technological conditions of berry juice.

Under the experimental conditions, the decisive impact on the performance indicators of the production of Crystal grapes was made by: shape of bush, the method of its maintenance and loading standard. We see that the highest parameters of loading (87 thousand bp / ha) were achieved in plantation with a small cupped form of bushes with a planting pattern of $3 \times 0.5 \mathrm{~m}$. The increase in the distance between the bushes to 1.5 $\mathrm{m}$ led to the decrease in loading standard 1.36 times (64 thousand bp / ha), which was shown Table 2.

It can be explained by the fact that the decrease in the number of plants per unit area leads to the increase in architectonics, i.e. their sizes, which go beyond the optimal ones for this method. As a result, growth processes in the vineyard are intensified, which lead to crown closure, in a limited small cupped formation by the crown space of the bush, and as a result, excessive thickening of shoots and leaf apparatus, as well as the decrease in the fruitfulness of shoots and photosynthetic activity of plants [6, 7, 11]. A similar reaction to the increase in the distance between plants was with the use of relatively small formations: Umbrella, Heart-shaped, Guillot. In this case, the size (habitus) of the bush does not grow in the space in the trellis plane, which leads to the decrease in the load of shoots and the yield of the bush [12].

It is also noted that the average long-term yield of the Crystal variety in plantations with a small cupped structure on a simplified single-wire trellis, with both bushes planting patterns, is in the range from 13.2 to $20.0 \mathrm{t} /$ ha (Table 2) which is significantly higher than, for example, in plantations with a high-stem 2-sleeved formation - 11.6 and $15.4 \mathrm{t}$ / ha. At the same time, there were no significant differences in the indicators of crop quality between the experimental variants. We should note good cumulative ability of sugar of Crystal grape variety. Even in the experiment with the maximum yield $(20.0 \mathrm{t} /$ 
TABLE 2: Influence of bushes' planting pattern and formation method on the performance indicators of the Crystal variety, 2011 - 2019.

Bush formation
Zigzag cordon
2-sleeved
high-punched
Y-type
Small cupped
Umbrella
Heart-shaped
HCP 0,5
Guillot without spurs
options

\begin{tabular}{|c|c|c|}
\hline \multicolumn{3}{|c|}{$\begin{array}{l}\text { Planting Loading Average pattern, } \\
\text { standard, mass } \mathrm{m} \times \mathrm{m} \text { th. bunches, } \\
\text { g shoots/ha }\end{array}$} \\
\hline $3 \times 1,5$ & 62 & 120 \\
\hline $3 \times 0,7$ & 71 & 129 \\
\hline $3 \times 1,5$ & 53 & 143 \\
\hline $3 \times 0,7$ & 67 & 133 \\
\hline $3 \times 1,5$ & 60 & 122 \\
\hline $3 \times 0,7$ & 71 & 125 \\
\hline $3 \times 1,5$ & 64 & 126 \\
\hline $3 \times 0,5$ & 87 & 114 \\
\hline $3 \times 1,5$ & 56 & 133 \\
\hline $3 \times 0,5$ & 86 & 118 \\
\hline $3 \times 1,5$ & 58 & 134 \\
\hline $3 \times 0,7$ & 93 & 108 \\
\hline $3 \times 1,5$ & 53 & 133 \\
\hline $3 \times 0,7$ & 67 & 113 \\
\hline $3 \times 1,5$ & 58 & 130 \\
\hline \multirow[t]{2}{*}{$3 \times 0,5-0,7$} & 77 & 120 \\
\hline & & 8,7 \\
\hline
\end{tabular}

\begin{tabular}{|l|}
\hline \\
Yreld \\
\hline of bushes, \\
\hline 5,5 \\
\hline 3,6 \\
\hline 5,2 \\
\hline 3,3 \\
\hline 4,6 \\
\hline 3,3 \\
\hline 5,9 \\
\hline 3,0 \\
\hline 5,2 \\
\hline 2,5 \\
\hline 5,7 \\
\hline 2,3 \\
\hline 4,4 \\
\hline 2,7 \\
\hline 5,2 \\
\hline 3,4 \\
\hline
\end{tabular}

Yield

t/ha

tha

12,6

17,1

11,6

15,4

10,3

15,8

13,2

20,0

11,5

16,5

12,7

15,6

9,7

13,8

11,7

16,3

1,4
Concentration in berry juice, $\mathrm{g} / \mathrm{dm}^{3}$

\begin{tabular}{|c|c|}
\hline sugar & $\begin{array}{c}\text { titrating } \\
\text { acid }\end{array}$ \\
\hline 209 & 4,9 \\
\hline 215 & 4,9 \\
\hline 218 & 4,7 \\
\hline 223 & 4,7 \\
\hline 209 & 4,8 \\
\hline 218 & 4,8 \\
\hline 210 & 4,7 \\
\hline 223 & 4,9 \\
\hline 216 & 5,0 \\
\hline 225 & 4,7 \\
\hline 216 & 4,9 \\
\hline 223 & 4,8 \\
\hline 232 & 5,0 \\
\hline 222 & 4,9 \\
\hline 212 & 4,9 \\
\hline 221 & 4,8 \\
\hline & \\
\hline
\end{tabular}

ha), a significant decrease in the sugar content in the berry juice did not occur, which was confirmed by the data in Table 2 .

\section{Discussion}

As a result of our experiments and analysis, we should note that, according to the characteristics of the reaction of plants to various agro-technical influences, a high adaptability of Crystal variety to the environmental conditions of Lower Don Region was determined. In almost all variants of the experiment, we noted the following: high fruitfulness of shoots and their productivity, as well as productivity of bushes with high technological conditions of berry juice. A more intensive (age-related) increase in the yield of bushes with rare plantings was noted in comparison with compacted plantings. 


\section{Conclusion}

In the conditions of Lower Don region, for open-earth high-stemmed vineyards of the industrial type of Crystal variety, the methods of maintaining bushes on one-twotier trellises with free development of shoots were more effective, with $3 \times 1.5 \mathrm{~m}$ planting pattern of bushes, with formations: zigzag cordon and Y-type. In intensivetype plantations $(3 \times 0.5 \mathrm{~m})$, the highest labor productivity and productivity of vineyards was noted during the use of a medium-standard small cupped formation on a simplified single-wire trellis $[2,13]$.

There were no significant differences between the experiment variants by the terms of yield quality. The maximum sugar content in the berry juice in Crystal variety was in yield from bushes formed according to Guillot system $-232 \mathrm{~g} / \mathrm{dm}^{3}$, and the minimum in the experiment variant of Y-type $-209 \mathrm{~g} / \mathrm{dm}^{3}$, with the acidity of the berry juice 4.8 and $5.0 \mathrm{~g} / \mathrm{dm}^{3}$ respectively.

The plantations with compacted and conventional planting of bushes during the formation of plants with relatively small bushes (small cupped, Umbrella, heart-shaped) have heavy fruiting earlier than others. Vine bushes with high stem formations: doublesided and zigzag cordons, Y-type and others enter heavy fruiting one year later [14, 15].

\section{Acknowledgement}

The authors express their gratitude to the administration of Don State Agrarian University for their support in the research. They are also grateful to all the reviewers who made their valuable contribution to this paper.

\section{Conflict of Interest}

The authors have no conflict of interest to declare.

\section{References}

[1] Egorov, E. A., Serpukhovitina, K. A. and Khudaverdov, E. N. (2002). Sustainable Grape Production. Status and Development Prospects. Krasnodar: North Caucasus Zonal Research Institute of Horticulture and Viticulture of the RAAS.

[2] Huseynov, S. N., Manatskov A. G. and Mayborodin, S. V. (2018). The Development of Technological Schemes for the Cultivation of Vineyards in the Don. Magarach. 
Viticulture and Winemaking, vol. 20, issue 4, pp. 24-26.

[3] (1978). Agrotechnical Studies on the Creation of Intensive Vine Plantations on an Industrial Basis. Novocherkassk: All-Russian. Research Institute of Viticulture and Winemaking.

[4] Dospekhov, B. A. (1985). The Methodology of Field Experience (With the Basics of Statistical Processing of Research Results) ( $5^{\text {th }}$ ed.). Moscow: Agropromizdat.

[5] Zakharova, E. I. (1964). Formation, Pruning and Loading of Grape Bushes. Rostovon-Don: Book.

[6] Huseynov, S. N. and Chigrik, B. V. (2013). Agrotechnical Aspects of Improving the Methods of Cultivation of Industrial Vineyards. Winemaking and Viticulture, vol. 4 issue 4, pp. 24-29.

[7] Morlat, R. (2008). Effects on Root System, Growth, Grape Yield, and Foliar Nutrient Status of a Cabernet franc Vine. Am. J. Enol. Vitic American journal of enology and viticulture, vol. 59, issue 4, pp. 364-374.

[8] (2003). Shevtsov, A.N., Popov V.I., Tolokov N.R. and others Viticulture with the Basics of Winemaking. Rostov-on-Don: Publishing House SKNTs VSh.

[9] Huseynov, S. N., Manatskov A. G. and Mayborodin, S. V. (2018). The Development of Technological Schemes for the Cultivation of Vineyards in the Don. Magarach. Viticulture and Winemaking, vol. 20, issue 4, pp. 24-26.

[10] Egorov, E. A., et al. (2004). Viticulture in Russia: Present and Future. Makhachkala: New Day.

[11] Anesi, A., et al. (2015). Towards a Scientific Interpretation of the Terroir Concept: Plasticity of the Grape Berry Metabolome. BMC Plant Biology, vol. 15, issue 1, p. 191.

[12] Avramov, L. (1986). Savremeno Podizanje Vinograda. Nolit. Beograd. -

[13] Keller, M. (2008). Interactive Effects of Deficit Irrigation and Crop Load on Cabernet Sauvignon in an Arid Climate. American journal of enology and viticulture., vol. 59, issue 3, pp. 221-234.

[14] Dennis, G. H. and Rogiers, S. Y. (2009). Water Flux of Vitis vinifera L. cv. Shiraz Bunches throughout Development and in Relation to Late-Season Weight Loss. American journal of enology and viticulture., vol. 60, issue 2, pp. 91-103.

[15] Egorov, E. A., et al. (2018). Priorities in the Technological Development of Industrial Viticulture. Magarach. Viticulture and Winemaking, vol. 20, issue 3, pp. 18-21. 